\title{
A INSTITUCIONALIZAÇÃO DO MOODLE COMO ESTRATÉGIA DE EXPERIMENTAÇÃO DO ENSINO HÍBRIDO NOS CURSOS PRESENCIAIS
}

\author{
THE INSTITUTIONALIZATION OF MOODLE AS A BLENDED LEARNING \\ EXPERIMENT STRATEGY FOR IN-CLASSROOM COURSES
}

\author{
Daiani Damm Tonetto RIEDNER ${ }^{1}$ \\ Carina Elisabeth MACIEL ${ }^{2}$
}

\begin{abstract}
Resumo:
Este estudo analisa o processo de institucionalização da Educação a Distância na Universidade Federal de Mato Grosso do Sul, por meio da implementação do Moodle para os cursos de graduação presenciais. O objetivo desta investigação é analisar como a institucionalização do Moodle se constituiu numa estratégia de experimentação do ensino híbrido. Esse estudo é um desdobramento de uma pesquisa interinstitucional realizada no período de 2016 a 2018. A base empírica das análises de uso do Moodle foi respaldada em documentos institucionais de 2019, além de um questionário aplicado aos professores que trabalharam com o Moodle nesse período. As análises apontam que o processo de institucionalização da $\mathrm{EaD}$ fomentou o trabalho pedagógico na perspectiva da aprendizagem híbrida por meio do uso do Moodle. Os professores se mostraram disponíveis para encarar o desafio da gestão da sala de aula virtual, para além de todas as responsabilidades pedagógicas no desenvolvimento das aulas presenciais.
\end{abstract}

Palavras-chave: Institucionalização. Educação a Distância. Moodle. Aprendizagem Híbrida.

\begin{abstract}
:
This study analyzes the Distance Education (DE) process of institutionalization at Universidade Federal do Mato Grosso do Sul, through the implementation of Moodle for in-classroom courses. The objective of this investigation is to analyze how Moodle institutionalization constituted a strategy for blended learning experimentation. This study is an offshoot of interinstitutional research conducted from 2016 to 2018. Institutional documents and reports from 2019, support the empirical basis of Moodle usage analysis, together with a questionnaire applied to professors who worked with Moodle in the same semester. The analyzes indicate that DE institutionalization has nurtured pedagogical work from the perspective of blended learning through Moodle. Professors showed a disposition to face the challenge of managing virtual classrooms, in addition to all responsibilities concerning the development of their in-classroom courses.
\end{abstract}

Keywords: Institutionalization. Distance Education. Moodle. Blended Learning.

\footnotetext{
${ }^{1}$ Docente UFMS - daiani.riedner@ufms.br

${ }^{2}$ Docente UFMS - carina.maciel@ufms.br
} 


\section{Introdução}

Esse estudo é um desdobramento da pesquisa “Institucionalização da Educação Superior a Distância nas Universidades Federais da Região Centro-Oeste: Processos, Organização e Práticas", realizada de forma interinstitucional no período de 2016 a 2018 e apoiada pelo $\mathrm{CNPq}^{3}$.

O objetivo central do texto é discutir e analisar de que forma a Educação a Distância (EaD) na Universidade Federal de Mato Grosso do Sul (UFMS), por meio da Universidade Aberta do Brasil (UAB), contribuiu para institucionalização do Moodle, que se constituiu como uma estratégia de experimentação do ensino híbrido nos cursos presenciais.

Como desdobramentos do objetivo central apresentamos as percepções e análises sobre o processo de institucionalização da educação a distância na UFMS, bem como discutimos de que forma esse processo (em curso) têm tencionado atualizações de normativas e implementação de tecnologias educacionais oriundas da educação a distância, com destaque para o Moodle, que é utilizado na instituição desde 2008.

Para construção dos dados sobre a experimentação do ensino híbrido nos cursos presenciais foi realizado um questionário online, de participação anônima e voluntária, que foi respondido pelos professores que solicitaram criação dos ambientes virtuais de aprendizagem no primeiro semestre de 2019. A consulta foi realizada ao final do período letivo do primeiro semestre e obtivemos 98 respostas das 325 que eram esperadas, pois essa foi a quantidade de ambientes virtuais solicitados no período. Tivemos uma média de $30 \%$ de adesão ao questionário, o que é esperado em pesquisas online. O questionário foi construído com nove questões relacionadas aos objetivos pedagógicos de uso do Moodle nos cursos presenciais.

Para a discussão que se propõe, o texto está organizado em quatro seções, a saber: 2) Trajetória da educação a distância na UFMS - nesse tópico vamos apresentar de forma breve a trajetória da EaD na UFMS, no que diz respeito aos aspectos organizacionais e pedagógicos; 3 ) Reflexões sobre o processo de institucionalização em curso - nesse tópico apresentaremos os dados e algumas análises sobre o processo de institucionalização da EaD no contexto da UFMS; 4) O Moodle na UFMS: trajetória de uso dos ambientes virtuais de aprendizagem e sua

\footnotetext{
${ }^{3}$ Chamada CNPq/ MCTI n. 25/2015 Ciências Humanas, Sociais e Sociais Aplicadas, sob número de processo 443725/2015-2. Site: http://www.cnpq.br/.
} 
implementação nos cursos presenciais - nesse tópico vamos apresentar a trajetória do Moodle desde a sua implementação na EaD até o uso nos cursos presenciais; 5) O Moodle como estratégia de experimentação do ensino híbrido - e no último tópico vamos discutir algumas estratégias de experimentação do ensino híbrido, a partir do uso do Moodle.

\section{Trajetória da educação a distância na UFMS}

Na UFMS, a EaD iniciou-se informalmente no ano de 1991 por meio do Grupo de Apoio ao Ensino de Ciências e Matemática no $1^{\circ}$ Grau - GAECIM. O grupo era composto por professores dos departamentos de Educação, Biologia, Física e Matemática e tinha como objetivo criar na UFMS um organismo interdisciplinar que oferecesse cursos a distância para qualificação dos professores da rede pública. (BATISTA; GOBARA, 2006).

No final da década de 1990, com o avanço do acesso à internet, surgiram as primeiras experiências de implantação de cursos de extensão e de especialização no âmbito da Assessoria de Educação Aberta e a Distância, em plataformas virtuais como o TelEduc ${ }^{4}$ e e-Proinfo, este último, uma plataforma destinada à oferta do Curso de Mídias na Educação ${ }^{5}$. (BATISTA; GOBARA, 2006).

A Portaria $n^{\circ} 332$, de 14 de agosto de 2000 oficializou a criação, implantação, divulgação e regimento interno da Assessoria de Educação Aberta e a Distância - AEAD na UFMS. A primeira oferta de graduação foi o curso de Pedagogia para o polo de Bela Vista MS. E primeira oferta de pós-graduação lato sensu foi o Curso de Especialização em Orientação Pedagógica em Educação a Distância, cujas vagas atenderam os profissionais da educação de municípios como São Gabriel do Oeste, Rio Brilhante, Camapuã, Campo Grande, além de técnicos da UFMS e comunidade em geral. (RIEDNER; BATISTA, 2018).

Em 2008, a UFMS aprovou sua primeira oferta de cursos de graduação e pós-graduação a distância pela UAB. E iniciou um trabalho desafiador para oferta de cinco cursos para doze polos da UAB, sendo três no Paraná e um em São Paulo. Nessa época, a EaD ainda era vista

\footnotetext{
${ }^{4}$ O TelEduc é um ambiente virtual de aprendizagem criado em 1997 pela Unicamp. Foi utilizado com intensidade no final da década de 90 por ser uma proposta inovadora de cursos online naquele período. $\mathrm{O}$ sistema ainda existe, mas não conseguiu acompanhar as inovações tecnológicas do Moodle. http://www.teleduc.org.br/. Acesso em: 26 jul. 2019.

${ }^{5}$ Os módulos Intermediário e Avançado do Curso de Mídias na Educação podem ser acessados online (conteúdo original das ofertas do e-Proinfo), pelo endereço: http://webeduc.mec.gov.br/midiaseducacao/index6.html\#. Acesso em: 26 jul. 2019.
} 
com desconfiança pela maioria dos docentes da instituição e grande parte do trabalho docente era executado por colaboradores externos, principalmente docentes de universidades privadas e docentes da educação básica que possuíam mestrado e/ou doutorado.

Depois da primeira oferta da $\mathrm{UAB}$, onde foram atendidos quatro polos externos ao Estado de Mato Grosso do Sul (MS), a UAB/CAPES orientou que as ofertas deveriam se limitar aos municípios do Estado para maior economia de recursos com passagens e diárias. Diante disso, a gestão institucional decidiu ofertar cursos apenas nos polos do Estado de MS, o que fomentou a criação de novos polos e expandiu as possibilidades de atendimento.

Atualmente, a UFMS oferta cursos a distância em seis polos, que são mantidos com os acordos de cooperação entre os municípios e a UAB/CAPES. E dois polos associados, cuja infraestrutura física é da instituição. Além dos polos, a UFMS tem mais sete Campus que foram habilitados pela Capes como polos associados, mas que ainda não receberam ofertas de cursos a distância.

Desde 2000, adaptada em um espaço da antiga biblioteca, a Coordenadoria de Educação Aberta e a Distância (CED) recebeu no ano de 2010 o seu espaço próprio, um prédio construído especificamente para abrigar as ações e projetos da $\mathrm{EaD}$ na instituição. O espaço foi equipado com novos computadores e mobiliários, com laboratório de informática e estúdio de gravação. Todo financiamento de custeio e material permanente foi oriundo dos recursos descentralizados por meio de edital específico da UAB/CAPES.

No ano de 2011, a estrutura organizacional da UFMS passou por mudanças com a publicação da Resolução COUN n ${ }^{\circ}$ 54, de 10 de novembro de 2011. E a CED, que era vinculada à Reitoria e funcionava como unidade de ensino voltou a fazer parte da Pró-Reitoria de Ensino de Graduação (PREG). O retorno à PREG fez com que a Coordenadoria perdesse a sua característica de unidade de ensino, obrigando os cursos e seus docentes a serem alocados nas unidades de ensino de acordo com suas áreas de atuação.

Esse processo foi visto por muitos docentes e técnicos como uma desestruturação da EaD na instituição e, por outros, como uma indução à institucionalização dos cursos, já que a transferência de responsabilidade da gestão dos cursos e a presença dos professores da EaD nas unidades de ensino poderia significar uma sensibilização e mobilização dos demais profissionais para conhecer e experimentar o trabalho pedagógico no ensino a distância. 


\section{HORIZONTES - REVISTA DE EDUCAÇÃO}

e-ISSN: 2318-1540

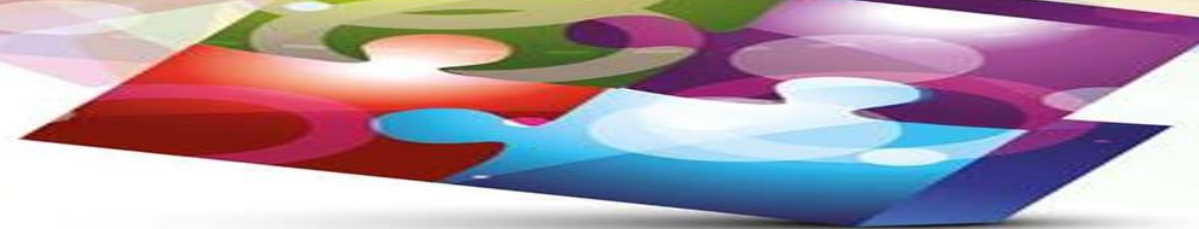

Com essa mudança estrutural, a CED/PREG permaneceu como uma unidade de apoio administrativo, tecnológico e de gestão financeira dos cursos, já que a gestão institucional da $\mathrm{UAB}$ e os recursos advindos dos projetos de curso não poderiam ser descentralizados para as unidades de ensino. No entanto, até o ano de 2019, das sete unidades de ensino que "receberam" os cursos em 2011, apenas duas absorveram a gestão acadêmica de forma plena. Nas demais unidades, essa demanda ainda está sob responsabilidade da unidade de apoio à EaD, mesmo não existindo, na sua estrutura organizacional, uma secretaria acadêmica.

Com a nova gestão (2016-2020), a Coordenadoria de Educação Aberta e a Distância (CED/PREG) e a Coordenadoria de Apoio à Formação de Professores (CFP/PREG) foram agregadas na criação da Secretaria Especial de Educação a Distância e Formação de Professores (SEDFOR), vinculada à Reitoria. (RESOLUÇÃO COUN n. 02, de 20 de janeiro de 2017).

A fusão das duas coordenadorias foi objeto de críticas e de protesto entre os professores e técnicos que atuavam na antiga CED, pois essa mudança também resultou na transferência do prédio construído em 2010 com recursos da UAB, para um novo espaço, denominado Centro de Formação de Professores. A SEDFOR teve que ser construída e precisou encontrar seus espaços de atuação, articulando a $\mathrm{EaD}$ (ofertas da UAB) com a formação inicial e continuada de professores do quadro e a formação continuada em articulação com o Comitê Gestor Institucional de Formação Inicial e Continuada de Profisssionais da Educação Básica (COMFOR), extinto em junho de 2019.

\section{Figura 1 - Trajetória administrativa da EaD na UFMS}

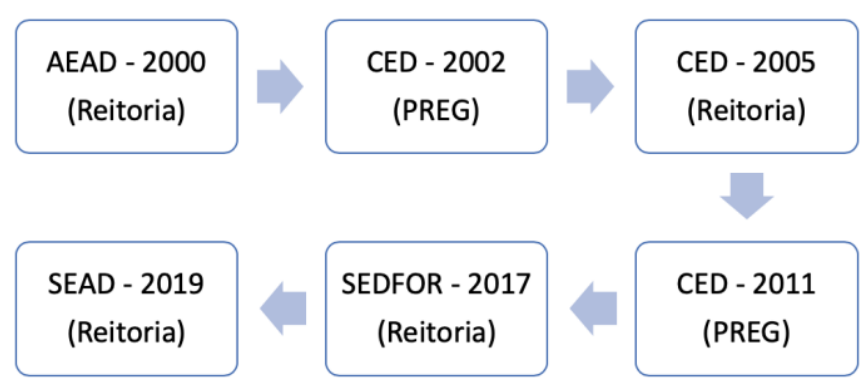

Elaboração das autoras, 2019.

A figura 1 representa a trajetória administrativa da $\mathrm{EaD}$ na perspectiva organizacional da UFMS desde o ano 2000, quando a instituição despertou para a necessidade de trabalhar com essa modalidade. Essas idas e vindas demonstram que esse "lugar" institucional foi objeto de muitas discussões, acertos e erros. 
Em 2019, a gestão percebeu a necessidade de desvincular a formação de professores do setor que gerencia a $\mathrm{EaD}$ e numa nova mudança na estrutura organizacional, a SEDFOR se transformou em Secretaria Especial de Educação a Distância (SEAD), vinculada à Reitoria, com uma definição bem clara de que o setor ocupa hoje um espaço de atividade meio, de apoio administrativo, tecnológico e pedagógico para ofertas de $\mathrm{EaD}$, não só por meio da $\mathrm{UAB}$, mas com abertura para outras parcerias e focalizando seus esforços principalmente na implementação da EaD nos cursos presenciais.

O modelo de EaD que prevalece na UFMS é o modelo híbrido, onde os momentos presenciais fazem parte do calendário acadêmico dos cursos de graduação e pós-graduação a distância e são de extrema importância para manutenção dos estudantes nos cursos. Isto porque a UFMS ainda não tem uma cultura consolidada de produção de material didático, devido às limitações internas na composição da equipe, tendo em vista que esses perfis técnicos são ocupados por funcionários terceirizados, em contratos temporários, de acordo com as possibilidades do orçamento advindos dos repasses de custeio da UAB/CAPES.

Com a diminuição dos recursos de custeio, as viagens aos polos de $\mathrm{EaD}$ vêm diminuindo desde o ano de 2015 e hoje o modelo que está sendo seguido por todos os cursos é de uma viagem ao polo, por disciplina e por semestre. Essa estratégia permite uma economia financeira que garante a presença do professor de cada disciplina no polo, pelo menos uma vez, para todos os cursos, nos dois semestres letivos do ano. No entanto, essa estratégia apresenta consequências na permanência dos estudantes nos cursos.

Como um “[...] objeto que procura representar um processo real”, Costa (2007, p. 9), diz que os modelos de ensino a distância devem se adequar às reais necessidades e especificidades dos estudantes de acordo com as regiões onde serão implantados. Esse processo real representa o processo possível dentro da instituição, considerando sua infraestrutura física e tecnológica, os recursos humanos, a experiência dos docentes, o perfil dos tutores, os projetos pedagógicos dos cursos e outros fatores que compõem o processo como um todo e que orientam as práticas e ações de todos os envolvidos na $\mathrm{EaD}$.

Como uma política de indução e de interiorização da educação a distância superior pública, desde a sua criação, a UAB permitiu às instituições públicas de ensino superior a criação de espaços institucionais para o desenvolvimento do ensino, da pesquisa e da extensão em prol do atendimento pleno e inclusivo aos alunos da EaD. Essa indução da UAB também 
contribuiu para mudanças nas práticas pedagógicas no contexto dos cursos. Essas mudanças foram tencionadas principalmente pelos professores que, num primeiro momento, foram contratados para atuarem apenas nos cursos a distância, mas foram gradativamente se integrando também aos cursos presenciais. Essa integração faz parte de um processo de institucionalização em curso, sobre o qual trataremos no próximo tópico.

\section{Reflexões sobre o processo de institucionalização em curso}

A institucionalização da EaD na UFMS é um processo que iniciou com as primeiras ofertas de cursos financiadas pela UAB. Desde 2008, a cada ano e a cada nova gestão institucional, têm se pensado e repensado as práticas e normativas para a regulação das ofertas da $\mathrm{EaD}$ na instituição, sempre levando em consideração as mudanças de legislação em âmbito nacional. No entanto, apesar dessas tentativas, algumas normativas não foram consolidadas, devido aos percalços na gestão administrativa e das constantes mudanças que demonstraram uma indefinição do lugar institucional da EaD na UFMS.

Com a criação da SEDFOR em 2017, houve uma aproximação desse lugar institucional e também uma definição das atribuições do setor responsável pela $\mathrm{EaD}$, o que fez com que o processo de institucionalização tivesse alguns avanços significativos, principalmente no que diz respeito às normativas internas da instituição.

Com o foco no Instrumento de Avaliação de Cursos do Sistema Nacional de Avaliação da Educação Superior - SINAES publicado em outubro de 2017, foram criadas algumas frentes de trabalho para análise do instrumento e proposição de normativas para regularizar a situação dos cursos a distância e para ofertas a distância nos cursos presenciais.

O primeiro passo foi a reformulação do regulamento geral do ensino de graduação ${ }^{6}$, que pela primeira vez incluiu a EaD no texto publicado em novembro de 2018. Até esta data, a EaD era amparada por uma normativa específica, que havia sido publicada em 2014 e que estava há muito tempo desatualizada, pois algumas práticas já não poderiam ser enquadradas em vários aspectos da resolução.

\footnotetext{
${ }^{6}$ Resolução COGRAD No 550, de 20 de Novembro de 2018.
} 
No mesmo período também houve a publicação da resolução ${ }^{7}$ que estabelece as normas regulamentadoras dos cursos de pós-graduação lato sensu, incluindo na mesma normativa as modalidades presencial e a distância. Até este momento, não havia uma regulamentação para pós-graduação lato sensu a distância na UFMS e as ofertas eram realizadas adaptando-se às regras dos cursos presenciais.

O conceito de institucionalização remete à ideia de dar a um serviço ou ação caráter de instituição e essa transformação requer mobilização, trabalho em equipe e articulação com a proposta de formação e o papel social da instituição, definida comumente no Plano de Desenvolvimento Institucional.

[...] cabe à própria instituição a tarefa e a responsabilidade de construir o processo de institucionalização da $\mathrm{EaD}$, considerando suas características, seu contexto, sua realidade regional, enfim, todo o seu entorno social, econômico, político e cultural. (SCHLÜNZEN JUNIOR, 2013, p. 115).

Para Kesar (2007), a institucionalização é definida como um processo caracterizado por rotinas "cristalizadas" com apoio legítimo e comprometimento de lideranças no desenvolvimento das ações no ambiente de trabalho. Pesquisadores como Kesar (2007), Kesar e Sam (2012) e Platt (2009) argumentam a existência de três fases do processo de institucionalização: a) mobilização, b) implementação e c) institucionalização. Essas três fases podem ocorrer simultaneamente e de forma dinâmica, não seguindo obrigatoriamente uma ordem linear e hierárquica.

$\mathrm{Na}$ fase de mobilização encontramos processos que podem contribuir para as decisões e cumprimento de uma política (PLATT, 2009). Durante a mobilização evidenciamos os processos de tomadas de decisão que podem culminar com a implementação de ações e políticas. Dentre esses processos destacamos: construção de pontos de referência, modelos, criação de força-tarefa, reuniões, obtenção de apoio externo, parcerias institucionais e criação de planos de ação (KESAR; SAM, 2012).

A implementação refere-se à materialização das ideias e/ou atividades, ou seja, colocase em prática as ações propostas. De acordo com Platt (2009), essa fase pode durar de seis meses até cinco anos. O processo da implementação é caracterizado pelo apoio às ações e criação de infraestrutura, bem como por estímulos e desestímulos no desenvolvimento das ações (KESAR;

\footnotetext{
${ }^{7}$ Resolução COPP No 280, de 29 de Novembro de 2018 que foi revogada pela Resolução COPP No 107, de 17 de Junho de 2019.
} 


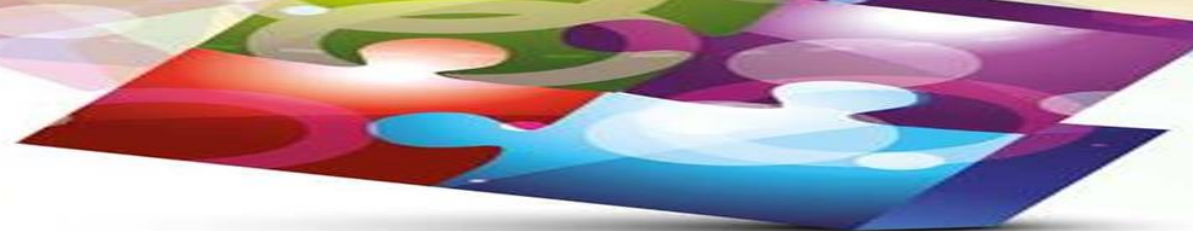

SAM, 2012). É importante destacar que nessa fase os debates têm foco na ação, já que a existência de agendas e reuniões para discussões estão mais definidas neste período (KESAR, 2007).

No processo de institucionalização existe a operacionalização viável de estruturas organizacionais, ações e atitudes que se tornaram rotina por mais de dois anos (PLATT, 2009). Pimenta e Anastasiou (2010), ressaltam que uma rotina engessada e burocrática pode tornar um obstáculo e inviabilizar o desenvolvimento de atividades na própria instituição.

Nesta perspectiva, a presença de apoio organizacional, padronização de procedimentos e a incorporação de valores e normas na cultura organizacional são fundamentais neste processo de institucionalização. A pesquisa de Ferreira e Mill (2013, p. 158) destaca a presença de cinco elementos como fatores importantes para a institucionalização da Educação a Distância:

1. Políticos e Filosóficos (Planejamento): estão associadas à vocação institucional para oferta de cursos superiores na modalidade, perspectivas de longo prazo e sustentáveis para adoção de políticas e procedimentos em $\mathrm{EaD}$ e fortalecimento da estrutura acadêmica colegiada.

2. Organização: capacidade em promover a articulação entre os cursos presenciais/à distância através do fortalecimento integrado entre as unidades acadêmicas e gestoras.

3. Infraestrutura: garantias de recursos físicos tecnológicos necessários à estruturação da gestão técnico-pedagógica e administrativa.

4. Pessoal: garantias à formação e qualificação de quadros necessários à condução de políticas de oferta dos cursos.

5. Políticas Discentes (Serviços ao Estudante): garantias de participação plena do corpo discente vinculado aos cursos EaD nas políticas universitárias, no acesso aos suportes acadêmicos e pedagógicos e auxílios destinados a eles.

Compreender e analisar o processo de institucionalização de uma política, programa, gestão ou ação contribui para a identificação dos fatores que influenciam sua implementação e seu fluxo de procedimentos desejados. Nessa perspectiva, olhamos para o processo de institucionalização da EaD na UFMS como um processo em curso, que ainda está na fase de mobilização, embora algumas ações já tenham sido implementadas. Isto porque, a institucionalização plena exige uma compreensão mais profunda dos processos que envolvem a EaD na instituição por todos os setores e pessoas envolvidas.

Essa compreensão demanda vivências desses processos, o que ainda não é uma realidade na instituição, pois a gestão da EaD ainda é centralizada na perspectiva da UAB e vários dos atores envolvidos, como tutores presenciais e a distância, assistentes a docência e 
coordenadores de polo, não são perfis institucionais e não há uma via de comunicação direta desses atores com a direção das unidades de ensino e pró-reitorias.

Esse modelo padrão da UAB criou uma via paralela da instituição que atrelava os polos de $\mathrm{EaD}$ ao setor de gestão da $\mathrm{EaD}$ e à coordenação UAB. Essa via caminhou por muito tempo sem o olhar da instituição, sem acompanhamento e avaliação de desempenho. Um importante avanço foi a inclusão parcial da EaD na avaliação institucional no ano de 2018.

Com a publicação da Resolução do Conselho de Graduação № 550, de 20 de Novembro de 2018, a instituição abriu a possibilidade de oferta de disciplinas a distância nos cursos presenciais. A aprovação do texto passou por uma grande mobilização e discussão, principalmente nas unidades que já ofertam cursos $\mathrm{EaD}$. No entanto, as ofertas a distância nos cursos presenciais não foram implementadas, pois o Sistema Acadêmico (SISCAD) ainda não foi programado para o entendimento dessas ofertas de acordo com a resolução.

Outro agravante para implementação da EaD no presencial foi a publicação da Portaria $\mathrm{N}^{\mathrm{o}} 1.428$, de 28 de Dezembro de 2018, pelo Ministério da Educação (MEC), pouco mais de um mês após a publicação da resolução na UFMS. Essa portaria dispõe sobre a oferta de disciplinas na modalidade a distância em cursos de graduação presenciais e indica que as disciplinas na modalidade a distância devem estar claramente identificadas na matriz curricular do curso e que o projeto pedagógico do curso deve indicar a metodologia a ser utilizada nestas disciplinas. Além disso, o Artigo 7 detalha outras exigências para implementação da EaD nos cursos presenciais.

Art. $7^{\circ} \mathrm{A}$ oferta das disciplinas previstas nos arts. $2^{\circ}$ e $3^{\circ}$ desta Portaria deverá incluir métodos e práticas de ensino-aprendizagem que incorporem o uso integrado de tecnologias de informação e comunicação - TIC para a realização dos objetivos pedagógicos, material didático específico, bem como a mediação de tutores e profissionais da educação com formação na área do curso e qualificados em nível compatível ao previsto no projeto pedagógico do curso - PPC e no plano de ensino da disciplina, que deverão descrever as atividades realizadas a distância, juntamente com a carga horária definida para cada uma, explicitando a forma de integralização da carga horária destinada às atividades on-line. (BRASIL, 2018, p. 1).

A publicação desta portaria deixou a resolução desatualizada e desarticulada com as exigências da normativa do MEC. A normativa anterior, com base na qual a Resolução 550 havia sido construída é a Portaria MEC n 1.134 , de 10 de outubro de 2016. Essa portaria orientava que os Projetos Pedagógicos de Curso deveriam ser atualizados de forma a prever ofertas de disciplinas a distância nos cursos presenciais, mas não exigia a descrição nominal 
das disciplinas, tampouco o detalhamento de metodologias, produção de material didático, práticas pedagógicas, tecnologias, tutoria e formas de avaliação dessas ofertas a distância, conforme consta na Portaria de 2018.

Essa situação de desarticulação das normativas fez com que uma ação em fase de implementação voltasse à etapa de mobilização, pois com as novas diretrizes, outras discussões e articulações institucionais foram iniciadas, na perspectiva de viabilizar as ofertas a distância nos cursos presenciais, englobando questões relativas à capacitação dos professores, produção de material didático, fluxo de gestão acadêmica e administrativa, estratégias e metodologias de oferta, tecnologias e avaliação da aprendizagem.

Em cada mobilização fomentada pela SEAD e realizada em parceria com os demais setores de gestão da instituição, um pequeno passo é dado em direção à institucionalização. São etapas necessárias para a implementação de ações importantes para consolidação da EaD na instituição. Um desses passos importantes foi a institucionalização do Moodle por meio da vinculação ao SISCAD. Essa mobilização, que começou em 2017 e foi implementada em 2019 é o objeto de discussão do próximo tópico.

\section{O Moodle na UFMS: trajetória de uso dos ambientes virtuais de aprendizagem e sua implementação nos cursos presenciais}

O Moodle (Modular Object Oriented Distance LEarning) é um software livre que funciona como uma sala de aula virtual, um ambiente virtual de apoio à aprendizagem, que faz parte dos sistemas de gerenciamento de aprendizagem chamados Learning Management System (LMS). Por ser um software livre, o seu desenvolvimento e atualizações são realizadas por um coletivo de pessoas que trabalham com programação em instituições ou de forma independente e que criam e compartilham em rede ${ }^{8}$ novas possibilidades e funcionalidades que podem potencializar as aprendizagens dentro do ambiente virtual. Além desse trabalho coletivo, ao instalar o Moodle, é possível customizá-lo de acordo com as necessidades de oferta e com os modelos de EaD que são utilizados na instituição.

\footnotetext{
8 A comunidade brasileira de desenvolvedores e usuários do Moodle pode ser acessada aqui: https://moodle.org/course/view.php?id=35.
} 
Antes da UAB, os cursos a distância na UFMS foram ofertados apenas com materiais impressos e aulas presenciais, sem nenhuma interação online. Eram cursos modulares, de finais de semana, em que os professores viajavam para os polos e ministravam suas aulas, iniciando na sexta-feira à noite e finalizando no domingo de manhã, cumprindo quatro períodos de carga horária intensos e sem muitos intervalos, para "transmitir" todo o conteúdo necessário às disciplinas.

Com o início das ofertas financiadas pela UAB em 2008, o uso do Moodle passou a ser obrigatório e ao mesmo tempo surgiram os perfis de apoio e acompanhamento dos estudantes, por meio da tutoria presencial e a distância, sendo que a tutoria a distância seria responsável por todo processo de aprendizagem dos estudantes online.

No primeiro momento, o sistema funcionou como um repositório de materiais de texto, com alguns fóruns de discussão e envio de tarefas também baseadas apenas em texto. Foi uma transposição do que já era feito de forma presencial para o formato digital. Num segundo momento, mas ainda de forma tímida, foram sendo produzidas e disponibilizadas as videoaulas dos professores. Sem estrutura e parâmetros para produção, a maioria dos vídeos eram extensos, maçantes e cansativos, mas era o principal canal de comunicação do professor com os estudantes.

O modelo ainda mantinha as aulas presenciais, mas agora com um período a menos, iniciando na sexta-feira à noite e finalizando no sábado a tarde. O uso do Moodle não articulava o processo de ensino aprendizagem como um todo, pois particionava e definia os momentos presenciais e atividades a distância de forma bem linear, muitas vezes sem articulação, pois o professor não acompanhava de perto o processo de aprendizagem, trabalho que era feito pelos tutores a distância de forma muito intensa.

Esse modelo prevaleceu por alguns anos. E na medida em que os atores envolvidos com a EaD (tutores, professores, coordenadores de polo, coordenadores de tutoria, coordenadores de curso e gestores institucionais) foram adquirindo experiência, de forma gradativa, novos usos foram sendo experimentados, novos plugins e recursos passaram a ser utilizados pelos professores, mas sempre com muita dependência de materiais estáticos de texto.

A primeira versão do Moodle instalada em 2008 foi a 1.9.8. Essa versão foi utilizada por nove anos sem nenhuma atualização ou melhorias. Esse fato se deve a algumas questões de gestão administrativa e de infraestrutura física e tecnológica. A antiga CED não tinha na sua 
estrutura organizacional unidades de gestão subordinadas a ela para atendimento de demandas pedagógicas ou tecnológicas. Além disso, ela nasceu à margem da instituição, no sentido de que seus processos, ações e ambientes de atuação, não foram discutidos e/ou apoiados pelas pró-reitorias de graduação, pós-graduação e pelo antigo núcleo de tecnologia, que gerenciava questões relativas aos sistemas da universidade, infraestrutura de rede e manutenção de computadores.

A coordenadoria tinha responsabilidade sobre todas as suas frentes de trabalho, desde a realização dos processos seletivos para os cursos, passando pela manutenção de sua rede de internet e de seus computadores, instalação e gerenciamento do Moodle, secretaria acadêmica centralizada (inclusive com um sistema paralelo de gerenciamento acadêmico, diferente do ensino presencial), secretarias de curso e apoio administrativo composto por profissionais externos à UFMS e estagiários para gerenciamento do Moodle (que por alguns anos fizeram o trabalho que hoje é realizado pelos professores dentro do ambiente virtual, pois neste momento não havia o entendimento do sistema como uma sala de aula virtual, mas como um repositório de conteúdos e, por isso, deveria ser um trabalho técnico).

Em 2013, por meio da Resolução no 31, de 17 de abril de 2013, o conselho universitário aprovou novas mudanças na estrutura organizacional da instituição e criou a Divisão de Apoio Tecnológico (DIAT), vinculada à Coordenadoria de Educação Aberta e a Distância. A Resolução n ${ }^{\circ}$ 43, de 18 de abril de 2013 do Conselho Diretor, que estabeleceu as competências da DIAT/CED caracterizou a unidade como responsável pelas "políticas de oferta de cursos e atividades mediadas por TICs (Tecnologias de Informação e Comunicação) de cursos de graduação, pós-graduação e extensão na modalidade à distância”. E a sua primeira competência (de uma lista de 25 competências que envolviam todas as responsabilidades para oferta de EaD) seria "propor, organizar e oferecer cursos de graduação, pós-graduação e extensão na modalidade a distância”. (BOLETIM OFICIAL, nº, 5524, 2013, p. 183).

Como uma ação estratégica institucional, a proposição, organização e oferta de cursos a distância não poderia ser atribuída a uma divisão de caráter técnico e operacional, tampouco a responsabilidade de "propor medidas necessárias à adequação de disciplinas, pré-requisitos, estruturas curriculares, semestralização, equivalências, aproveitamento de estudos, bem como a integralização de disciplinas afins, na modalidade a distância", que seria uma responsabilidade das coordenações de curso, junto às unidades de ensino. 
Esse documento demonstra o quanto a EaD estava desarticulada da instituição e abarcava competências das pró-reitorias e das unidades de ensino. De fato, o trabalho desenvolvido pela DIAT/CED era de apoio tecnológico, que envolvia ofertas de cursos de capacitação para o Moodle e suporte técnico para a EaD, especialmente para o sistema de Webconferência.

A criação da SEDFOR em 2017 destinou para a EaD três unidades administrativas subordinadas e com um entendimento da gestão de que a EaD deveria ser uma política e responsabilidade da instituição e não apenas do setor de gerenciamento da $\mathrm{EaD}$, todas as responsabilidades de manutenção do Moodle foram transferidas para a Agência de Tecnologia da Informação e Comunicação (AGETIC). Essa transferência de responsabilidade trouxe a possibilidade de atualização do sistema, antes impedida pela falta de espaço nos servidores locais. Em julho de 2017, a versão 3.1.2 foi instalada no servidor geral da universidade e passou a ser monitorado por toda a equipe de desenvolvedores responsáveis pela manutenção do sistema. Em 2019, a UFMS já está utilizando a última versão do sistema (3.7.1).

Desde 2013, o Moodle começou a ser utilizado por cursos e atividades que não estavam diretamente relacionados à $\mathrm{EaD}$, tais como disciplinas presenciais dos cursos de graduação, cursos de extensão presenciais, grupos de pesquisa, grupos de trabalho, etc. A partir de 2017 o sistema também despertou o interesse dos cursos de pós-graduação stricto sensu presenciais. Foram criados 26 ambientes de apoio a esses cursos de no período de 2017 a 2019, sendo 19 ambientes apenas no ano de 2019.

Com um trabalho intenso que começou a ser desenvolvido em agosto de 2018, no início do ano de 2019 a AGETIC integrou a forma de solicitação dos ambientes virtuais ao SISCAD. Até então, os professores interessados em criar salas virtuais para suas disciplinas tinham que preencher um formulário e aguardar análise e aprovação para sua criação.

Com essa integração, o professor visualiza na aba de controle das aulas um botão com o ícone do Moodle e, ao clicar nesse botão, solicita a criação de um ambiente virtual da respectiva disciplina. O sistema roda um script e cria a sala virtual para a disciplina, importando também os estudantes matriculados. No dia seguinte da solicitação, o professor já pode acessar o ambiente com o seu passaporte institucional, incluir documentos, tarefas, fóruns e criar um canal de comunicação com os alunos. 
Cabe destacar que em 2019.1 houve um salto significativo de solicitações de ambientes virtuais no Moodle para os cursos de graduação presenciais, devido à integração com o SISCAD. No primeiro semestre de 2019, 325 professores solicitaram a criação de ambientes virtuais para suas disciplinas presenciais. Dos 325 professores que criaram os ambientes virtuais em 2019.1, 98 responderam à consulta. E dos 98 respondentes, $75 \%$ utilizaram de forma efetiva o/s ambiente/s criado/s.

Os dados mostram que a maioria dos professores (47,3\%) tem mais de 3 anos de experiência com uso do Moodle. E 27\% dos professores estão usando o sistema pela primeira vez. Esse dado confirma a importância da integração ao SISCAD, pois essa ação alcançou professores que não tiveram experiências anteriores com $\mathrm{EaD}$ ou com o Moodle e que não teriam oportunidade de fazer essa experimentação de uso de outra forma.

$\mathrm{Na}$ cidade universitária, houve representação de todas as unidades de ensino e das diversas áreas do conhecimento, sendo que os professores das áreas de exatas e biológicas foram predominantes nas solicitações. Em oito, das nove unidades de ensino nos Campus do interior houve representação dos professores nas solicitações.

No que diz respeito à capacitação para uso do Moodle, $54,1 \%$ dos professores indicaram que não realizaram nenhum curso de capacitação e 45,9\% dos respondentes realizaram curso de capacitação. Ao final da consulta, deixamos uma questão aberta para que os professores pudessem registrar as suas percepções sobre a iniciativa da UFMS em institucionalizar o uso do sistema, integrando-o ao SISCAD. E nesse espaço aberto, alguns professores demonstraram interesse em capacitações para melhor compreensão das possibilidades de uso e consequente aperfeiçoamento do trabalho.

A percepção dos professores sobre a institucionalização do Moodle é bastante positiva. Elencamos abaixo alguns relatos que demonstram o alcance institucional, pedagógico e estratégico dessa ação.

O uso do Moodle no ensino presencial é muito importante, pois ajuda o professor no desenvolvimento das atividades, na aproximação mais dos estudantes e também colabora para diminuição do uso de papel. (Professor Anônimo 1).

Muito boa iniciativa, auxilia a comunicação entre o docente e os acadêmicos e facilita a apresentação de conteúdos. (Professor Anônimo 2).

O Moodle permite melhor organização dos conteúdos para os alunos. (Professor Anônimo 3). 
Considero extremamente importante a iniciativa. Isso possibilitou agilização do processo de solicitação do ambiente virtual, incentiva professores a adotarem a plataforma e cria uma cultura de acesso à plataforma também entre os alunos. (Professor Anônimo 4).

Excelente, pois o curso de formação de docente direcionou que as aulas fossem inovadoras e com o Moodle percebi que há uma conexão segura de aula híbrida. (Professor Anônimo 5).

Além disso, a desburocratização do processo de solicitação aliada à inscrição automática dos estudantes são aspectos que contribuíram para aproximar mais o professor do uso do Moodle nos cursos presenciais. Os professores também destacaram a importância de um canal institucionalizado para comunicação com os estudantes, o que garante mais segurança na comunicação, para resguardar o professor e os estudantes de eventuais problemas relacionados às falhas de comunicação.

Outro ponto importante que foi destacado por cinco professores que responderam à consulta é a necessidade de integração do sistema de notas do Moodle com o SISCAD. Esse é o próximo passo da institucionalização, a integração do sistema de avaliação da aprendizagem do Moodle com o Sistema Acadêmico, o que irá diminuir a possibilidade de equívocos no lançamento das notas, além de facilitar o trabalho do professor, que hoje precisa lançar notas nos dois sistemas.

\section{O Moodle como estratégia de experimentação do ensino híbrido}

Não deixamos de falar quando se inventou a escrita, nem deixamos de escrever, quando foi possível imprimir palavras no papel. E nem mesmo agora com as tecnologias, onde as palavras são digitalizadas, haverá desvalorização das demais formas de comunicação e informação. Pelo contrário, as tecnologias digitais conformam todas as maneiras de comunicar. E permitem maior acesso aos diferentes tipos de textos midiáticos, que também são falados, impressos e digitalizados. Marcovitch (2002, p. 4) destaca que "O crescimento do volume e dos meios de acesso às comunicações exige uma nova atitude mental das pessoas e das instituições".

Nesse novo cenário comunicacional, no campo da educação, a interatividade ganha força na medida em que a transmissão (emissão separada da recepção) perde seu espaço. A 
participação vai além da escolha entre duas ou mais opções de resposta, mas abre espaço para modificação da própria mensagem. É o movimento que demonstra a “[...] transição da lógica da distribuição (transmissão) para a lógica da comunicação (interatividade)" (SILVA, 2004, p. $6)$.

O autor ressalta ainda que, mesmo a sala de aula sendo rica em tecnologias, não será interativa se prevalecer a "pedagogia da transmissão", que considera o estudante um receptor passivo, como um depósito de informações e conhecimentos. Essa interatividade na cultura digital aproxima mais do estudante a responsabilidade pela aprendizagem, que não pode permanecer apenas centrada no "falar-ditar" do professor.

Nessa perspectiva, o professor pode ser um agente de transformação da lógica da sua sala de aula na medida em que vai disponibilizar múltiplas oportunidades de participação aos seus estudantes. "Ele predispõe teias, cria possibilidades de envolvimento, oferece ocasião de engendramentos, de agenciamentos. E estimula a intervenção dos estudantes como co-autores de suas ações" (SILVA, 2004, p. 9).

O ensino híbrido se constitui como uma integração orgânica de abordagens, metodologias, estratégias didáticas e tecnologias que podem ser desenvolvidas de forma presencial e/ou online de acordo com cada contexto de experimentação. Trata-se de uma oportunidade de repensarmos fundamentalmente as nossas concepções de ensinoaprendizagem, que insistem em colocar o espaço físico da sala de aula tradicional como o lócus principal do processo formativo da universidade.

Apesar das inseguranças que ainda perpassam esses projetos de experimentação, o ensino híbrido pode estimular mudanças institucionais, curriculares, pedagógicas, metodológicas e tecnológicas nas universidades, com o propósito de desenvolver, cada vez mais, a construção de práticas pedagógicas inovadoras, que tenham foco na aprendizagem e na personalização do ensino.

O ensino híbrido tem como principal objetivo melhorar o aproveitamento do tempo do professor e estimular um maior engajamento dos estudantes nas atividades propostas, o que pode garantir um melhor aprendizado. No entanto, não existe uma fórmula e não pode ser encarado como um método rígido, com etapas ou fases que devem ser seguidas à risca. Pelo contrário, a proposta do ensino híbrido considera que cada estudante aprende no seu tempo, tem suas particularidades, dificuldades e potencialidades. (HORN; STAKER, 2015). 
Sabemos que o ensino considerado tradicional, mesmo nas melhores universidades, não tem dado conta de atender as necessidades dos estudantes que vivem imersos na cultura digital. (KENSKI, 2013). Nessa perspectiva, a proposta do ensino híbrido é reunir o que há de melhor do ensino online com o melhor do ensino tradicional (presencial), da sala de aula que conhecemos e estamos bem acostumados. (BACICH; NETO; TREVISANI, 2015).

Criar um ambiente virtual atrelado a uma disciplina presencial não garante que o professor desenvolva uma abordagem híbrida. Para que isso aconteça, é necessário que o professor crie estratégias de uso do Moodle que sejam contextualizadas e integradas ao que é realizado na sala de aula presencial. Além disso, uma das principais vantagens da abordagem híbrida do ensino é a possibilidade do acompanhamento individualizado dos estudantes.

As principais motivações dos professores para uso do Moodle podem ser divididas em quatro categorias: a) como um repositório de conteúdos e materiais; b) para o desenvolvimento de atividades e para avaliação da aprendizagem; c) como um canal de comunicação com os estudantes; e d) personalização do ensino, sendo esta categoria com a menor indicação de interesse de uso pelos professores.

Como o grande desafio da proposta do ensino híbrido para a educação, a personalização precisa ser iniciada por meio de um projeto, uma ação conjunta entre o professor e seus estudantes, para que seja feito o delineamento individual do processo de aprendizagem e seleção dos recursos que melhor se encaixam nos diferentes ritmos de aprendizagem. Cada estudante tem necessidades diferentes e se relaciona de forma diferente com o professor, com os outros estudantes e com as tecnologias digitais. $\mathrm{O}$ aprendizado não acontece do mesmo ritmo, no mesmo tempo, no mesmo lugar e do mesmo modo. (BACICH; NETO; TREVISANI, 2015).

Diante disso, o ensino online tem potencial para contribuir com a personalização, uma vez que pode ajudar a preencher lacunas no processo de aprendizagem. Alguns recursos digitais permitem que o professor acompanhe mais de perto o seu estudante, podendo propor atividades específicas para ele de acordo com seu desempenho e suas dificuldades. Em turmas muito numerosas, torna-se quase impossível fazer isso presencialmente, pois demandaria muito tempo e ainda assim não seria proveitoso, pois o tempo de atendimento de um estudante deixaria os demais estudantes ociosos e sem supervisão.

Nessa perspectiva, o ambiente virtual de aprendizagem é a tecnologia mais utilizada para esse acompanhamento, onde é possível fazer a convergência de inúmeros outros recursos 
digitais, atividades, organização de conteúdos e ferramentas de acompanhamento e feedback da aprendizagem dos estudantes.

As estratégias de uso do Moodle pelos professores ainda são bem estáticas, como repositório de textos e slides, que não demandam do estudante muita participação dentro do espaço virtual, além da visualização e leitura dos materiais disponíveis. As atividades de envio de arquivo têm por vantagem a economia de papel, mas não é possível mensurar se as estratégias de realização dessas atividades garantem colaboração em rede entre os estudantes. A Wiki é um recurso de produção de texto colaborativo e foi a estratégia menos utilizada. Os fóruns de discussão, que são recursos mais simples e importantes para trocas de experiências foram utilizados em $50 \%$ dos ambientes criados.

O Chat é um recurso de bate-papo síncrono (em tempo real) e ficou em segundo plano, já que é um recurso cujo uso depende da disponibilidade de todos os participantes num determinado dia e horário. Na maioria dos casos, o fórum pode substituir o chat, pois dá uma abertura de tempo maior para os estudantes programarem suas participações. Além disso, as comunicações rápidas que não são relacionadas aos conteúdos em si, são resolvidas em aplicativos de bate-papo pelo smartphone ou dentro do próprio Moodle, dependendo do canal de comunicação que for definido pelo professor.

A quantidade de videoaulas de autoria dos professores também foi bastante tímida e está relacionado à própria experiência de produção de material didático digital, que ainda não é de total domínio pelos professores que atuam preferencialmente nos cursos presenciais. Já os vídeos e videoaulas produzidos por terceiros foi um recurso bastante utilizado, mas ainda menos do que os fóruns de discussão.

Os recursos foram elencados de acordo com o grau de dificuldade de criação/utilização dentro do Moodle. Dessa forma, com base nos dados apresentados, podemos delinear um perfil de seu uso, que se mostra básico e cujo nível de dificuldade para criação/utilização é baixo.

Esse perfil de professores é um perfil que tem grande potencial de inovação das práticas pedagógicas a partir do uso do Moodle, pois se mostraram disponíveis para encarar o desafio da gestão da sala de aula virtual, que requer um trabalho de pesquisa, curadoria, organização, criação e sistematização de materiais, recursos digitais e atividades, para além de todas as responsabilidades pedagógicas para o desenvolvimento das aulas presenciais. 
MORIZONTES - REVISTA DE EDUCAÇÃO

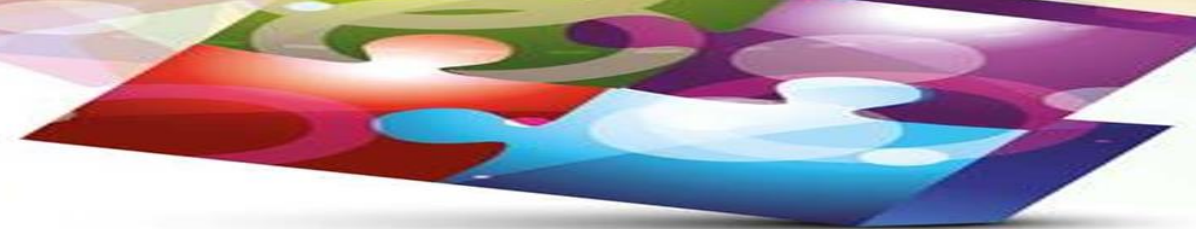

Trabalhar na perspectiva da aprendizagem híbrida é um desafio que não depende apenas da vontade do professor, mas de um conjunto de ações institucionais, infraestrutura física e tecnológica, formação continuada dos professores e um clima institucional que seja favorável à inovação pedagógica e que tenha como princípio norteador o sucesso na aprendizagem dos estudantes.

\section{Considerações finais}

O processo de institucionalização da $\mathrm{EaD}$ que está em curso desde 2008 com a implementação da UAB, teve significativo avanço a partir de 2017 quando foi criada uma Secretaria Especial, vinculada à Reitoria, dando maior visibilidade às ações da EaD na instituição e estreitando a articulação com os polos de apoio presenciais para o planejamento e registro das demandas de formação inicial e continuada, além de induzir o uso de metodologias e tecnologias do ensino a distância para a inovação das práticas pedagógicas nos cursos presenciais.

Como nas demais instituições públicas de educação superior, a EaD na UFMS é organizada levando em consideração as características regionais e locais, que visam o desenvolvimento de uma educação a distância pública e de qualidade, concatenando conhecimentos científicos e tecnológicos, assim como a institucionalização de ações, práticas e tecnologias.

A instituição também tem trabalhado na discussão, criação e publicação de normativas internas que envolvem a elaboração de projetos pedagógicos de curso, definição das metodologias de oferta, estratégias de avaliação da aprendizagem online, modelos de tutoria, fluxos de produção de material didático, atribuições da equipe multidisciplinar e outros elementos que regem todo o processo de oferta de cursos e disciplinas nessa modalidade.

Hoje é perceptível um esforço institucional para que a EaD seja fortalecida na graduação e na pós-graduação, para expandir as possibilidades de oferta e oportunizar experiências de aprendizagem diferenciadas, levando em consideração o perfil dos estudantes que estão cada vez mais imersos na cultura digital.

Como uma política de indução da $\mathrm{EaD}$, a UAB teve uma diminuição dos recursos de custeio e bolsas desde 2014 e aos poucos tem adequado suas ofertas com um estudo minucioso 
das demandas de formação existentes nos polos e municípios do entorno, focalizando em cursos que são prioritários para atendimento principalmente da formação inicial e continuada de professores.

Com esse cenário, as instituições têm adaptado seus recursos e modificado as metodologias de oferta dos cursos para poder continuar ofertando $\mathrm{EaD}$ com qualidade e responsabilidade social, que é a marca registrada da educação a distância pública, gratuita e de qualidade. Essas mudanças chegaram também aos cursos presenciais. E levará um tempo para que os paradigmas da aprendizagem também sejam repensados, a fim de unir as melhores estratégias, sejam presenciais ou a distância, sempre levando em consideração o perfil e as necessidades de aprendizagem de cada um dos estudantes que compõem o universo formativo da universidade.

As abordagens híbridas aliadas ao uso do Moodle tencionam o professor a abandonar métodos e práticas tradicionais de ensino. Ao professor não cabe, nesta abordagem, somente a transmissão de conceitos, mas sim a criação de ambientes favoráveis para a aprendizagem. Para os estudantes, o ensino híbrido pode modificar a postura passiva da aprendizagem, uma vez que eles desenvolvem saberes e práticas por meio do uso de tecnologias digitais contextualizadas às situações de aprendizagem, como práticas culturais e pedagógicas que fazem a convergência do uso social para o uso pedagógico de tecnologias.

O ensino híbrido aliado ao uso do Moodle nos cursos presenciais não é uma fórmula ou uma receita para a inovação pedagógica. Mas a experimentação do Moodle na perspectiva da aprendizagem híbrida, com seus recursos, metodologias e tecnologias podem indicar caminhos diversos, que serão trilhados de acordo com concepção de ensino e aprendizagem de cada professor, bem como de acordo com suas condições reais (institucionais, tecnológicas, pedagógicas e de formação) e disposição para implementar novas propostas.

\section{Referências}

BACICH, Lilian; NETO, Adolfo Tanzi; TREVISANI, Fernando de Mello. (Org.). Ensino híbrido: personalização e tecnologia na educação. Porto Alegre: Penso, 2015.

BATISTA, Erlinda Martins; GOBARA, Shirley T. As concepções de professores de um curso a distância sobre o papel do fórum on-line. Revista Brasileira de Estudos Pedagógicos, 


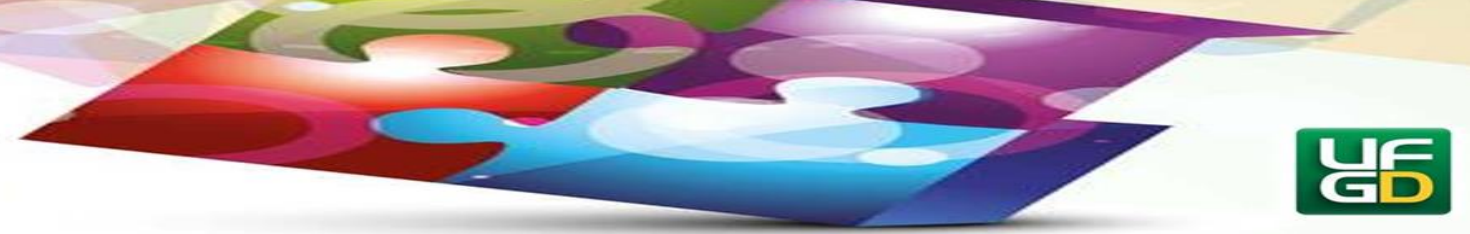

Brasília, v. 87, n. 216, maio/ago. 2006. Disponível em: http://bit.ly/2LIKusN. Acesso em: 26 jul. 2019.

BRASIL. Portaria $n^{\circ} 1.428$, de 28 de dezembro de 2018. Dispõe sobre a oferta, por Instituições de Educação Superior - IES, de disciplinas na modalidade a distância em cursos de graduação presencial. Brasília: Diário Oficial da União. [2018]. Disponível em: http://bit.ly/2GWyiAr. Acesso em: 20 jul. 2019.

BOLETIM OFICIAL. Portaria Reitoria $n^{\circ} 332$, de 14 de agosto de 2000. Cria a Assessoria de Educação Aberta e a Distância da UFMS. Campo Grande: Boletim Oficial n ${ }^{\circ}$ [?] UFMS. [2000].

BOLETIM OFICIAL. Resolução Conselho de Pesquisa e Pós-Graduação no 107, de 17 de Junho de 2019. Estabelece as Normas Regulamentadoras dos Cursos de Especialização, nas modalidades presencial e a distância, da Fundação Universidade Federal de Mato Grosso do Sul (UFMS). Campo Grande: Boletim Oficial no 7065 UFMS. [2019]. Disponível em: http://bit.ly/2PjtdXW. Acesso em: 20 jul. 2019.

BOLETIM OFICIAL. Resolução Conselho de Pesquisa e Pós-Graduação $n^{\circ} 280$, de 29 de Novembro de 2018. Estabelece as Normas Regulamentadoras dos Cursos de Pós-Graduação Lato Sensu da UFMS. Campo Grande: Boletim Oficial nº 6932 UFMS. [2018]. Disponível em: http://bit.ly/2MIB8MS. Acesso em: 20 jul. 2019.

BOLETIM OFICIAL. Resolução Conselho Diretor $n^{\circ} 43$, de 18 de abril de 2013. Fixa as competências das Unidades integrantes da Estrutura Organizacional da Pró-Reitoria de Ensino de Graduação da Universidade Federal de Mato Grosso do Sul. Campo Grande: Boletim Oficial no 5524 UFMS. [2013]. Disponível em: http://bit.ly/32NF9Fw. Acesso em: 20 jul. 2019.

BOLETIM OFICIAL. Resolução Conselho Diretor $n^{\circ}$ 54, de 10 de Novembro de 2011. Fixar as competências da unidades integrantes da estrutura organizacional da Pró-Reitoria de Ensino de Graduação. Campo Grande: Boletim Oficial no 5176 UFMS. [2011]. Disponível em: http://bit.ly/2BSVHjD. Acesso em: 20 jul. 2019.

BOLETIM OFICIAL. Resolução Conselho Universitário $n^{\circ}$ 2, de 20 de Janeiro de 2017. Altera a Estrutura Organizacional da Fundação Universidade Federal de Mato Grosso do Sul. Campo Grande: Boletim Oficial n ${ }^{\circ} 6470$ UFMS. [2017]. Disponível em:

http://bit.ly/2BSVHjD. Acesso em: 20 jul. 2019.

BOLETIM OFICIAL. Resolução Conselho Universitário no 31, de 17 de Abril de 2013. Aprovar a alteração da Estrutura Organizacional da Pró-Reitoria de Ensino de Graduação. Campo Grande: Boletim Oficial no 5524 UFMS. [2013]. Disponível em: http://bit.ly/2JkEjbu. Acesso em: 20 jul. 2019.

COSTA, Celso José. Modelos de Educação Superior a Distância e Implementação da Universidade Aberta do Brasil. Revista Brasileira de Informática na Educação, Porto Alegre, v. 15, n. 2, maio./ago. 2007. Disponível em: http://bit.ly/2YwKlhY. Acesso em: 28 jul. 2019. 


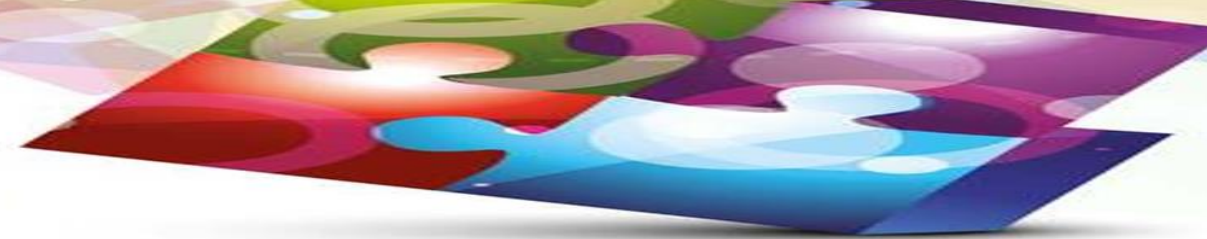

FERREIRA, Marcello; MILL, Daniel. Institucionalização da educação a distância no ensino superior público brasileiro: desafios e estratégias. In: FIDALGO, F. S. et al. (Org.). Educação a distância: meios, atores e processos. Belo Horizonte: CAED-UFMG, 2013.

HORN, M. B.; STAKER, H. Blended: Usando a inovação disruptiva para aprimorar a educação. [tradução: Maria Cristina Gularte Monteiro]. Porto Alegre: Penso, 2015.

KENSKI, Vani Moreira. Tecnologias e tempo docente. Campinas, SP: Papirus, 2013.

KESAR, Adrianna; SAM, Cecile. Strategies for implementing and institutionalizing new policies and practices: understanding the change process. In: KESAR, Adrianna (Ed.). Embrancing non-tenure track faculty: changing campuses for the new faculty majority. New York: Routledge, 2012.

KESAR, Adrianna. Tools for a Time and Place: Phased leadership Strategies to Institutionalize a Diversity Agenda. The Review of Higher Education, v. 30, n. 4, 2007. Disponível em: http://bit.ly/2GBxUHt. Acesso em: 28 jul. 2019.

MACIEL, Carina Elisabeth. et al. A institucionalização da educação superior a distância na Universidade Federal de Mato Grosso do Sul: processos, organização e práticas. Acta Qualidade, Tecnologias e Educação a Distância, Campo Grande, v. 1, n. 4, abr. 2018.

MARCOVITCH, Jacques. A informação e o conhecimento. São Paulo em Perspectiva, São Paulo, v. 16, n. 4, dez. 2002.

MARTÍN-BARBERO, JESÚS. Nuevos regímenes de visualidad y des-centramientos educativos. Revista de Educación, Espanha, n. 338, set./dez., 2005. Disponível em: $<$ https://bit.ly/2Im5EHR>. Acesso em: 15 maio. 2018.

PIMENTA, Selma Garrido; ANASTASIOU, Léa das Graças Camargo. Docência no Ensino Superior. Coleção Docência em Formação. 2. Ed. São Paulo: Cortez, 2005.

PLATT, Phyllis A. Promoting Change Through a school-Based Model of Comprehensive Student and Family Support. Kentucky's Family Resource and Yuoth Services Centers. In: 21st National Symposium on Doctoral Research in Social Work. Ohio State University. College of Social Work. University of Kentucky. Lexington, KY. 2009. Disponível em: http://bit.ly/2K9025F. Acesso em: 28 jul. 2019.

RIEDNER, Daiani Damm Tonetto Riedner. Práticas pedagógicas e tecnologias digitais no ensino superior: formação inicial de professores e inovação na UFMS. Rio de Janeiro, 2018. 181p. Tese de Doutorado - Departamento de Educação, Pontifícia Universidade Católica do Rio de Janeiro.

RIEDNER, Daiani Damm Tonetto; BATISTA, Erlinda Martins. Trajetória da educação a distância na UFMS: desafios para a institucionalização. Revista Intersaberes, v. 13, n. 29, mai./ago, 2018. Disponível em: http://bit.ly/2X5AgnM. Acesso em: 26 jul. 2019. 


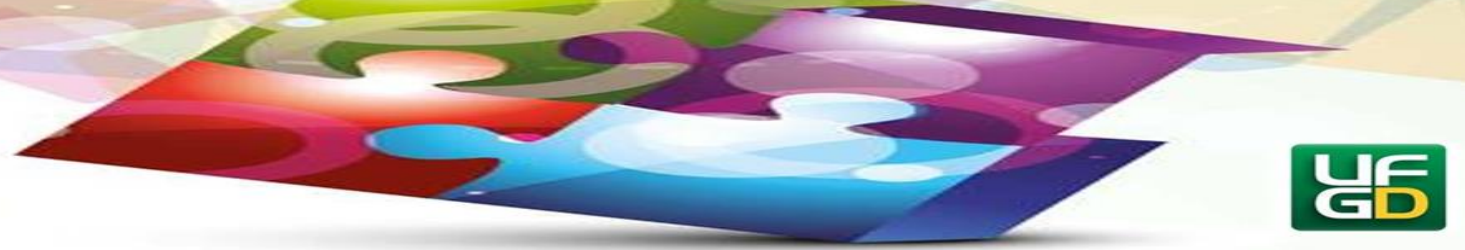

SCHLÜNZEN JUNIOR, Klaus. A institucionalização da educação a distância no Brasil: cenários e perspectivas. Rev. Teoria e Prática da Educação, Maringá, v. 16, n. 1, Jan./Abr. 2013. Disponível em: http://bit.ly/2Yw1Wqq. Acesso em: 26 jul. 2019.

SILVA, Marco. Indicadores de interatividade para o professor presencial e online. Revista Diálogo Educacional, v. 4, n. 12, maio./ago. 2004. Disponível em: <https://bit.ly/2nwu7Bg>. Acesso em: 15 maio. 2018.

Data do envio do trabalho: 09/08/2019

Aprovado em: 17/11/2019

Publicado em: 18/12/2019 